$10 \%$ for allocation decisions), and still performed well in terms of other important attributes such as data collection speed, would still be the most useful to farmers as they could use the same device for dat across all decision contexts.

\section{Conclusions}

This study provides a first attempt at explicitly defining the important attributes for pasture measurement devices. It provides a guide to the attributes to consider, and some operational performance metrics, for the development of these devices and systems. We engaged with specialists in Australia and Ireland, as well a New Zealand, and while the research was targeted a New Zealand situations, the results can be adapted for guiding technology development and use in other pasture-based dairy systems internationally. Pasture data needs of different end users, such as multi-farm businesses, owner-operators, farm staff, and farm consultants are still to be determined.

\section{ACKNOWLEDGEMENTS}

This study was funded by New Zealand dairy farmer through DairyNZ Inc. in partnership with the Ministry of Primary Industries Primary Growth Partnership funding. The authors sincerely thank the experts who took part in the surveys.

\section{REFERENCES}

Dalley, D.; Clark, D.; Pairman, D.; Dynes, R.; Yule, I, King, W.; Mata, G. 2009. Technologies for measuring grass/crops. pp. 134-151. In: Proceedings of the South Island Dairy Event. Lincoln, New Zealand.

Dela Rue, B.T.; Eastwood, C.R. 2017. Individualised feeding of concentrate supplement in pasture-based dairy systems: practices and perceptions of New Zealand dairy farmers and their advisors. Animal Production Science 57: 1543-1549.

Eastwood, C.R.; Dela Rue, B.T.; Gray, D.I. 2017. Using a 'network of practice' approach to match grazing decision-support system design with farmer practice. Animal Production Science 57: 1536-1542.

Eastwood, C.R.; Jago, J.G.; Edwards, J.P.; Burke, J.K. 2016. Getting the most out of advanced farm management technologies: roles of technology suppliers and dairy industry organisations in supporting precision dairy farmers. Animal Production Science 56: 1752-1760.

Eastwood, C.R.; Kenny, S. 2009. Art or science? Heuristic versus data driven grazing management on dairy farms. Extension Farming Systems Journal 5: 95-102.

Edwards, J.P.; Dela Rue, B.T.; Jago, J.G. 2015. Evaluating rates of technology adoption and milking practices on New Zealand dairy farms. Animal Production Science 55: 702-709.

Hasson, F.; Keeney, S. 2011. Enhancing rigour in the Delphi technique research. Technological Forecasting and Social Change 78: 1695-1704.

Hirst, C.; Donaghy, D.; Gray, D.; Wood, B.; McCarthy, S. 2014. Exploring operational management used by dairy farmers to manage grazing. pp. 62-64. In: Proceedings of the 5th Australasian Dairy Science Symposium. Hamilton, New Zealand.

King, W.M.; Rennie, G.M.; Dalley, D.E.; Dynes, R.A.; Upsdell, M.P. 2010. Pasture Mass Estimation by the C-DAX Pasture Meter: Regional Calibrations for New Zealand. pp. 233-238. In: Proceedings of the 4th Australasian Dairy Science Symposium 2010. Lincoln, New Zealand. Caxton Press, Christchurch.

Linstone, H.A.; Turoff, M. 1975. The Delphi method : techniques and applications. Addison-Wesley Pub. Co. Advanced Book Program, Reading, Mass.

McCarthy, S.; Hirst, C.; Donaghy, D.; Gray, D.; Wood, B. 2014. Opportunities to improve grazing management. Proceedings of the New Zealand Grassland Association 76: 75-80.

Pullanagari, R.R.; Yule, I.J.; Tuohy, M.; Dynes, R.; King, W. 2011. Pasture quality measurement tools for decision making. In: Adding to the knowledge base for the nutrient manager. Occasional Report No. 24. Eds. Currie, L.D.; Christensen, C.L. Fertilizer and Lime Research Centre, Massey University, Palmerston North, New Zealand.

Thomson, N.A.; Upsdell, M.P.; Hooper, R.; Henderson, H.V.; Blackwell, M.B.; McCallum, D.A.; Hainsworth, R.J.; Macdonald, K.A.; Wildermoth, D.D.; Bishop Hurley, G.J.; Penno, J.W. 2001. Development and evaluation of a standardised means for estimating herbage mass of dairy pastures using the rising plate meter. Proceedings of the New Zealand Grassland Association 63: 149-157.

\title{
Optical sensors for variable rate nitrogen application in dairy pastures
}

K. WIGLEY ${ }^{1}$, J.L. OWENS ${ }^{2}$, J.A.K. TRETHEWAY ${ }^{3}$, D.C. EKANAYAKE ${ }^{1}$, R.L. ROTEN ${ }^{1}$ and A. WERNER ${ }^{1}$ Lincoln Agritech Ltd., PO Box 69133, Lincoln, Canterbury 7640, New Zealand ${ }^{2}$ Agriculture and Life Sciences Faculty, PO Box 84, Lincoln University 7647, Lincoln, New Zealand ${ }^{3}$ Syngenta Crop Protection, Private Bag 92618, Auckland, New Zealand kathryn.wigley@lincolnagritech.co.nz

Abstract

Reducing the amount of nitrogen $(\mathrm{N})$ fertiliser applied to dairy pastures down to agronomically optimised levels would have positive economic and environmental results. The ability of commercially available optical sensors to estimate biomass yield and foliar-N uptake in pastures was investigated. Vegetative indices (Simple Ratio, SR; Water Index, WI; and Normalised Difference Vegetation Index, NDVI) from two active optical reflectance sensors (N-Sensor, Yara; and Greenseeker, Trimble) were compared with manually measured biomass and $\mathrm{N}$-uptake in above-ground foliage. There were three measurements over time, from pastures that had received different $\mathrm{N}$ fertiliser applications rates $(0$, $10,20,40$ and $80 \mathrm{~kg} \mathrm{~N} / \mathrm{ha}$ ). It was found that the sensors were able to detect differences in biomass and foliar $\mathrm{N}$-uptake following defoliation of grazed pastures. The tested opticat sensors have the potential to inform a real-time variable rate fertiliser application system.

Keywords: pasture, nitrogen, optical sensors

\section{Introduction}

Modern intensive dairy farms inherently have low nitrogen use efficiency (NUE) (Powell et al. 2010). Lower N-fertiliser application to pastures at a comparable yield level would provide economic benefits to farmers who could spend less money on fertiliser. It could also benefit the environment by reducing the potential for nitrate leaching and nitrous oxide emissions (Maharjan et al. 2014). To reduce $\mathrm{N}$-fertiliser application and to determine the optimal rate of $\mathrm{N}$ required for different dairy pastures, strategies to quickly measure dry matter (DM) yields and pasture N-uptake are needed. One way to do this is by using optical sensors to infer vegetation indices such as NDVI, SR, and WI, which are calculated from reflectance values, and have been successfully related to plant yields and foliar N (Pullanagari et al. 2011; Roberts et al. 2015). By using optical sensors to detect areas of high $\mathrm{N}$ in pastures, such as areas with a large number of urine patches (Haynes \& Williams 1993; Jarvis et al. 1995), a variable rate system could avoid further fertiliser application to those areas, thereby improving NUE. Commercial optical sensors for efficient application of $\mathrm{N}$-fertiliser have been developed for intensive arable farming (Bragagnolo et al. 2013; Portz et al. 2012), but no such sensors have been developed for dairy pastures. The objective of this study was to test the performance of various vegetation indices (NDVI, WI, SR) measured from optical reflectance sensors to estimate biomass yield and $\mathrm{N}$-uptake in an irrigated dairy pasture.

\section{Methods}

The experiment took place at Lincoln University' Ashley Dene Research and Development Station $\left(43^{\circ} 38^{\prime} 42.0^{\prime \prime} \mathrm{S}, 172^{\circ} 20^{\prime} 33.0^{\prime \prime} \mathrm{E}\right)$ in Canterbury, New Zealand. The experiment was established on a stony, well-drained silty loam Balmoral Acidic Orthic Brown Soil (Hewitt 2010), with increasing stony sandy gravels beyond $15 \mathrm{~cm}$ depth. The newly established yearold past rennial ryegras Lolium perenne ), mixed with Italian ryegrass (Lolium multiflorum ), plantain (Plantago lanceolata) and white clover (Trifolium repens). Before establishment of thi pasture, the site was unirrigated and sheep-grazed.

The experimental area was subdivided into sixteen $12 \times 35 \mathrm{~m}$ plots. On the 11 October 2016, before the experiment started, the pasture was grazed by dairy cows. Following grazing, on 13 October 2016, urea certiliser was aplied at five rates $(0,10,20,40$ and by hand. Each fertiliser tratment was replicated three times in a randomised block design. During the experiment, the area was irrigated using a centre-pivot irrigator, as required. The plots were grazed again by dairy cows on the 31 October 2016 before the first data collection.

Sward reflection measurements using the sensors and calculating the vegetation indices were completed three times: 1,2 and 3 weeks post-grazing on 7 Novere 5 November, and 22 November 2016, respectively. Manual biomass collection was completed within 2 days of the sensor measurements.

\section{Biomass harvesting}

Biomass was harvested from within each plot from five $0.5 \times 0.5 \mathrm{~m}$ quadrats located along the middle axis of each plot. At each harvest, plants from each quadra were cut using hand-shears to a height of $\sim 5 \mathrm{~cm}(\sim 1500$ 


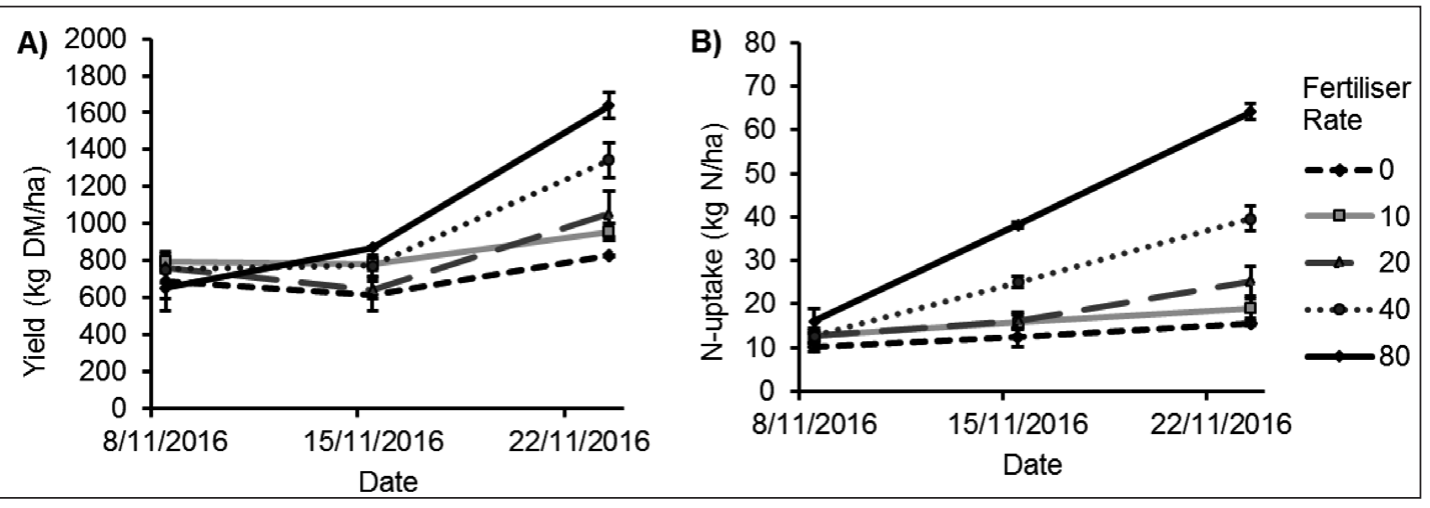

Figure 1 A) mean DM yields $( \pm S E M ; n=9)$, and $B$ ) mean $N$-uptake $( \pm S E M ; n=9)$ of plots receiving five different fertiliser treatments $(0,10,20,40$ and $80 \mathrm{~kg} \mathrm{~N} / \mathrm{ha}$ ) over one grazing cycle for the plots that were harvested 8,15 and 22 November 2016.

$\mathrm{kg} \mathrm{DM} / \mathrm{ha}$, Haultain et al. 2014). Fresh biomass was individual plots at a height of $1 \mathrm{~m}$ (Field of view: 61 weighed and then oven-dried for up to 48 hours at 68 ${ }^{\circ} \mathrm{C}$ before dry weights were recorded. Dry biomass was cround and used to dermine Total Nitrogen (TN, \%) using the Dumas combustion method on a Vario Max CN Element Analyser (Elementar Analysensysteme $\mathrm{GmbH}$, Germany).

Optical sensing of vegetation indices

Two active optical reflectance sensors were used to measure vegetation indices. The first was a tec- 5 ALS (Active Light Source) sensor, a research versio of the commercially available Yara N-Sensor (Yara Deutschland GmbH \& Co. KG, Dülmen, Germany). This sensor was equipped with a xenon flash light that emits light in a range between 650 to $1100 \mathrm{~nm}$ onto the canopy, and offers reflectance data from four optically filtered wavelength channels $(730,760,900,970 \mathrm{~nm})$ (Erdle et al. 2011). It provides values for SR $\left(R_{780} / R_{670}\right)$ and water index (WI) $\left(R_{900} / R_{970}\right)$ (Erdle et al. 2011). The sensor was tractor mounted and connected at a $45^{\circ}$ angle at a height of $203 \mathrm{~cm}$ above the ground, and was equipped with a real-time kinetic global positioning system (Model R10, Trimble Navigation Limited, Sunnyvale, California, USA) and a laptop. The tractor speed was $0.5 \mathrm{~m} / \mathrm{s}$ during measurements. On each of the 3 days that measurements were taken, the tractormounted sensor measured each of the 16 plots three times (longitudinally at 3,6 and $9 \mathrm{~m}$ along the $12 \mathrm{~m}$ wide axis of the $12 \times 35 \mathrm{~m}$ plots), to obtain spatially representative samples.

The second sensor was a hand-held Greenseeker (Trimble, Sunnyvale, California, USA) that return values for NDVI $\left(\left(R_{780}-R_{670}\right) /\left(R_{780}+R_{670}\right)\right)$ (Erdle et al. 2011). This sensor works by emitting light in the range of $\sim 660-770 \mathrm{~nm}$, and uses the pseudo reflectance to calculate the NDVI (Erdle et al. 2011). The average reading per plot was taken by passing the sensor over the middle of the longitudinal axis of each of the 16 $\mathrm{cm})$

\section{Data analysis}

Data analysis was completed using Microsoft ExcelTM The average SR and WI per plot was calculated. Nitrogen-uptake was determined by dividing the dry biomass weight $(\mathrm{g})$ by $\% \mathrm{~N}$ as a fraction of one, and converting to a mass per area $(\mathrm{kg} \mathrm{N} / \mathrm{ha})$. Using the data collected from all fertilisation treatments, linear regression models were computed between DM yield $(\mathrm{kg} / \mathrm{h}$ ) and each of the vegetation indices (NDVI, WI, $\mathrm{N}$-uptake $(\mathrm{kg} / \mathrm{ha})$ and the vegetation indices.

\section{Results}

The influence of nitrogen application on yield and foliar-N

Immediately following defoliation, no increase in biomass was observed up to $40 \mathrm{~kg} \mathrm{~N} / \mathrm{ha}$. The early increase in foliar- $\mathrm{N}$ and subsequent increase in dry matter yield resulted in a liner incease in N-uptake (kg N/ha) in all tead in a liner ince 83 Nove

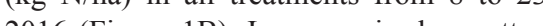
2016 (Fine 1B). Increases in diy thatter yield in al treatments ranged from $21 \%$ in the control to $155 \%$ in the $80 \mathrm{~kg} \mathrm{~N} / \mathrm{ha}$ treatment (Figure 1A). Over the same time, $\mathrm{N} \%$ in the foliage increased from $1.5-2.4 \%$ to $2-4.4 \%$, followed by a decrease to $1.9-3.9 \%$, as dry matter yield increased for all fertiliser treatments.

Optical sensors detect differences in dry matter yield and $\mathrm{N}$-uptake

The optical sensor measurements were related to the dry matter yield (Figure $2 \mathrm{~A}-\mathrm{C}$ ). While the $\mathrm{R}^{2}$ value suggests a linear relationship between dry matter yield and NDVI (Figure $2 \mathrm{~A}$ ), and WI (Figure 2B), both relationships showed some non-linear characteristics, with points above the line at the high and low end of the indices, and below the line in the mid-range of
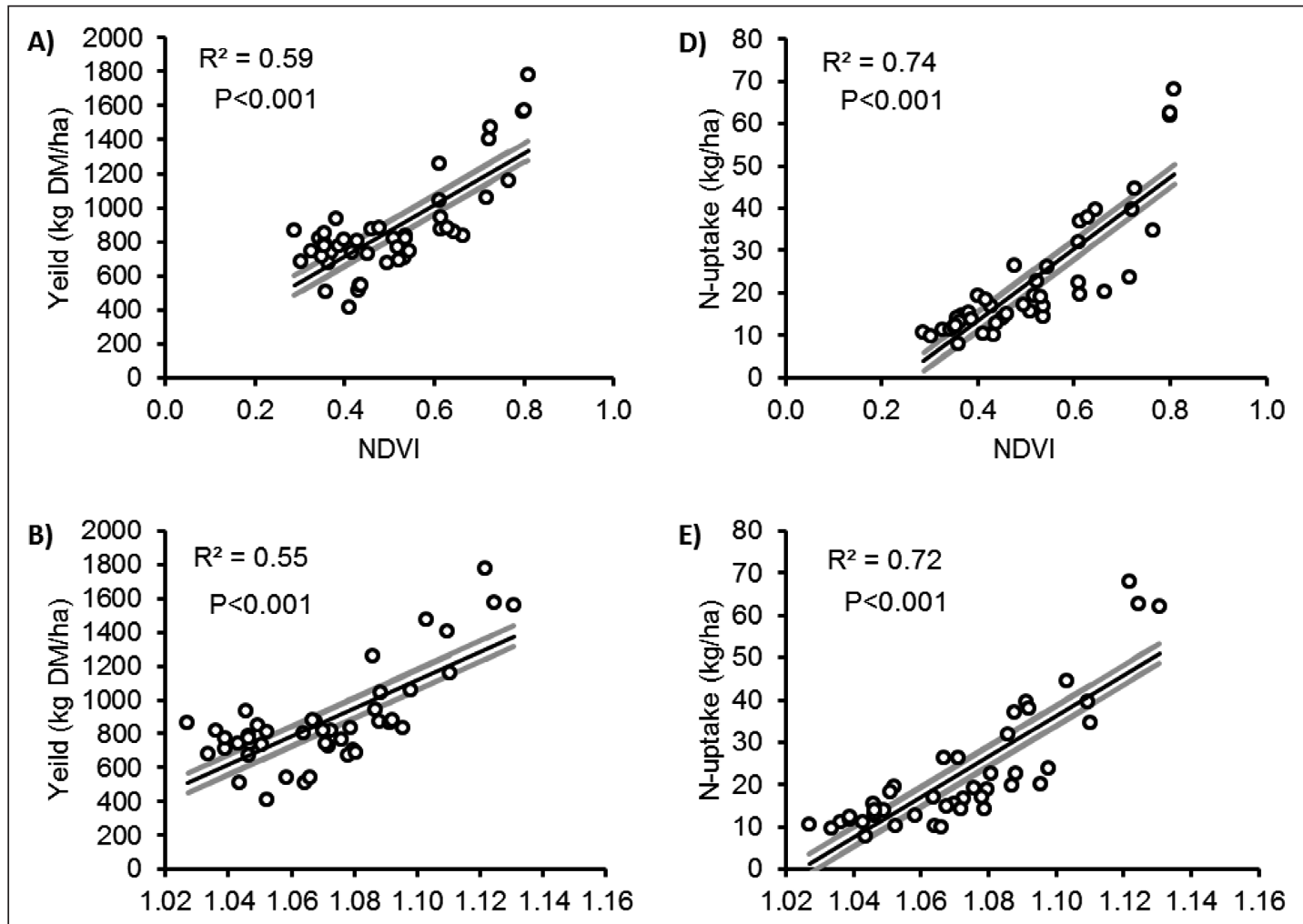

WI
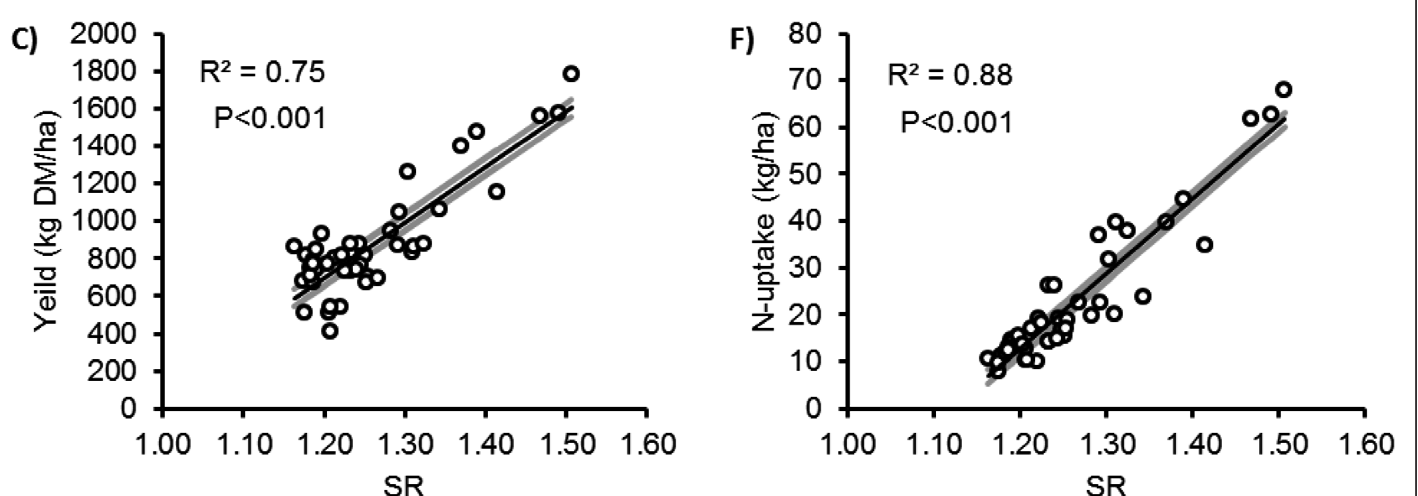

Figure 2 Relationships between dry matter yield (kg DM/ha) and: A) the normalised difference vegetation index, B) the water index, and C) the simple ratio. Relationships between nitrogen-uptake and: D) the normalised difference vegetation index, $E$ ) the water index, and $F$ ) the simple ratio. Each graph shows the coeffich of determination ( $\left.R^{2}\right)$, and level of

the indices. Similar trends were observed between N-uptake and NDVI (Figure 2 D), and WI (Figure 2 E) where data showed a similar curvature about the linear trend line. The relationships between SR and dry matter yield (Figure $2 \mathrm{C}$ ), and N-uptake (Figure $2 \mathrm{~F}$ ), showed strong and distinctive linear relationships between the variables with little scatter.
Discussion

Vegetation indices to detect changes in N-uptake and plant biomass

As expected, higher rates of $\mathrm{N}$-accumulation in plan foliage and greater dry matter yields were associated with higher $\mathrm{N}$-fertilisation rates, which are consistent with previous findings (Monaghan et al. 2005). All 
tested vegetation indices measured by the optical sensors were able to detect differences in dry matter yield and $\mathrm{N}$-uptake in the pasture plants.

Strong relationships between WI and dry matter yields in grass-only pastures, and weaker relationships for pastures mixtures of ryegrass and white clover, have been reported from measurements made using a Yara active optical reflectance spectrometer (Roberts $e t$ al. 2015), similar to the one used in the current study. The current study demitity of the SR pastures (ryegrass-clover) that are typical of irrigated cattle-grazed pasture. The strong relationship between $\mathrm{SR}$ and N-uptake is especially promising because $\mathrm{N}$-uptake is considered to be a robust agronomic parameter for determining site specific $\mathrm{N}$-fertilisation (Portz et al. 2012). However, other studies have noted the influence of season on the ability of active optical sensor output to relate to biomass due the effects of senescence (Trotter et al. 2012). Future work is require to verify the suitability of the use of the SR index for variable rate fertilisation in grazed and irrigated pastures by repeating the experiment with variations of the pasture plant species used in this study, at differen plant ages and times of the year, and at different pasture densities.

The visible deviations from linearity observed with the use of NDVI and WI are an important finding given the wide range of $\mathrm{N}$ conditions induced by the different rates of fertilisation. Others have similarly reported non-linear behaviour between NDVI and dry matter yield (Trotter et al. 2012) and N-uptake (Bragagnolo et al. 2013). This work provides a reference fo interpretation of results in future studies that have no implemented, or do not have available, such a wide range of $\mathrm{N}$. Over a smaller $\mathrm{N}$ range, the curvature in the data may not be apparent. Pastures grazed by cattle are likely to have sporadic areas of high $\mathrm{N}$ and biomass due to unine patches, which can cover $20 \%$ of a pasture, annually (Mir et al. 2011). Without a conprese understang (Man understanding of what causes of the curvatures in the data (lack of instrument sensitivity, the need for calibration, or plant factors such as age, density of the pasture, etc.) and a suitable compensation method, there is a risk that using NDVI or WI to make decisions related to variable rate fertilisation may lead to under or over application of fertiliser.

\section{Feasibility of sensors use on-farm}

The optical sensors tested in this study have the benefit of providing simple outputs, as well as flexible mounting options so the sensors can be deployed on available farm infrastructure (i.e. tractor, irrigator) The accuracy and precision of the data obtained from these devices is dependent on the angle of view and height at which they are mounted (Kipp et al. 2014). These factors along with further investigation into what influences the relationship between these indexes and dry matter and N-uptake are needed. For example, what factors cause the curvature in the data, need to be identified before a variable rate fertiliser application system could be used by farmers.

\section{Conclusions}

Active optical sensors offer the potential to develop real time variable rate $\mathrm{N}$-fertilisation systems. Of the measured indices, SR showed the most linear and consistent relationships to N-uptake and dry matter yields over a range of foliar-N conditions. The ability to apply $\mathrm{N}$-fertiliser in the right place, at the right time, and in the right amount, will increase NUE and reduce environmental impacts of N-loss in grazed pasture systems.

\section{ACKNOWLEDGEMENTS}

This work was funded through a grant from The New Zealand Ministry of Business Innovation and Employment under project, Optimum N - Nitrogen Sensing and Management (contract No.: CONT29854-BITR_LVL). We would like to express special thanks to the staff at Centre for Soil and Environmental Research, Lincoln University, for timely completion of the biomass and nitrogen analysis.

\section{REFERENCES}

Bragagnolo, J.; Carneiro Amado, T.J.; da Silveira Nicoloso, R.; Jasper, J.; Kunz, J.; de Grefori Teixeira, T. 2013. Optical crop sensor for variable-rate nitrogen fertilisation in corn: I - plant nutrition and dry matter production. Brazilian Journal of Soil Science 37: 1288-1298.

Erdle, K.; Mistele, B.; Schmidhalter, U. 2011. Comparison of active and passive spectral sensors in discriminating biomass parameters and nitrogen status in wheat cultivars. Field Crops Research 124:

Haultain, J.; Wigley, K.; Lee, J.M. 2014. Rising plate meters and a capacitance probe estimate the biomass of chicory and plantain monocultures with similar accuracy as for ryegrass-based pastures. Proceedings of the New Zealand Grassland Association 76: 67-74. and soil fertility in the grazed Advances in Agronomy 49: 119-199.

Hewitt, A.E. 2010. New Zealand soil classification. Landcare Research Science Series No. 1. 3rd Ed. Manaaki-Whenua Press, Lincoln, New Zealand.

Jarvis, S.C.; Lovell, R.D.; Panayides, R. 1995. Patterns of methane emission from excreta of grazing animals. Soil Biology and Biochemistry 27: 1581-1588.
Kipp, S.; Mistele, B.; Schmidhalter, U. 2014 The performance of active spectral reflectance sensors as influenced by measuring distance, device temperature and light intensity. Computers and Electronics in Agriculture 100: 24-33

Maharjan, B.; Venterea, R.T.; Rosen, C. 2014. Fertilizer and irrigation management effects on nitrous oxide emissions and nitrate leaching. Agronomy Journal 106: 703-714.

Moir, J.L; Cameron, K.C.; Di, H J; Fertsak, U. 2011. The spatial coverage of dairy cattle urine patches in an intensively grazed pasture system. The Journal of Agricultural Science 149: 473-485.

Monaghan, R.M.; Paton, R.J.; Smith, L.C.; Drewry, J.J.; Littlejohn, R.P. 2005. The impacts of nitrogen fertilisation and increased stocking rate on pasture yield, soil physical condition and nutrient losses in drainage from a cattle-grazed pasture. New Zealand Journal of Agricultural Research 48: 227-240.

Portz, G.; Molin, J.P.; Jasper, J. 2012. Active crop sensor to detect variability of nitrogen supply and biomass on sugarcane fields. Precision Agriculture 13:33-44. Powell, J.M.; Gourley, C.; Rotz, C.; Weaver, D. 2010 Nitrogen use efficiency: A potential performance indicator and policy tool for dairy farms. Environmental Science and Policy 13: 217-228.

Pullanagari, R.R.; Yule, I.; King, W.; Dalley, D.; Dynes, R. 2011. The use of optical sensors to estimate pasture quality. International Journal on Smart Sensing and Intelligent Systems 4: 125-137.

Roberts, J.; Suarez Infiesta, A.; Schäbitz, B.; Fourie, J.; Werner, A. 2015. Active optical sensing of canopies in pasture management. Journal of New Zealand Grasslands 77: 35-40

Trotter, M.G.; Schneider, D.; Lamb, D.; Edwards, C.; McPhee, M. 2012. Examining the potential for active optical sensors to provide biomass estimation in mproved and native pastures. In: Proceedings of the New England, Australia. 4 pp. 